\title{
Stress cardiomyopathy following acute ischemic stroke during flexible bronchoscopy: a rare sequence of complications
}

\author{
Cardiomiopatia induzida por stress após acidente vascular cerebral \\ isquêmico agudo durante broncoscopia flexível: uma rara sequência de \\ complicações
}

\author{
Sonja Badovinac, Marta Korsic, Branka Cucevic, Valentina Slivnjak, Andrea Vukic \\ Dugac, Marko Jakopovic
}

\section{To the Editor:}

Flexible bronchoscopy is a routine procedure used in a wide spectrum of airway pathologies, with a rare incidence of severe complications. We would like to present a case of a rare and odd sequence of complications in a patient treated in our clinic. A 74-year-old woman who had metastatic angiosarcoma in the thoracic wall, with known multiple pulmonary metastases, previously treated with chemotherapy, and without medical history of vascular diseases was admitted to our clinic due to hemoptysis and fever. At admission, the neurological status of the patient was unremarkable, and the patient showed no signs of chest pain. Baseline electrocardiogram (ECG) revealed no significant findings (Figure $1 \mathrm{~A}$ ). Laboratory tests revealed normocytic anemia (hemoglobin, $97 \mathrm{~g} / \mathrm{L}$; hematocrit, $0.295 \mathrm{~g} / \mathrm{L})$, leukocytosis $\left(10.9 \times 10^{9}\right.$ cells $\left./ \mathrm{L}\right)$, and elevated C-reactive protein $(219.4 \mathrm{mg} / \mathrm{L})$. Signs of renal or hepatic impairment were not registered. Fiberoptic bronchoscopy was indicated, and a blood clot was found in the left lower lobe bronchus. After the aspiration of the clot, there were no signs of active bleeding. During the procedure, the patient became unresponsive, presented with mydriasis, and stopped breathing but showed no alterations in heart rhythm. The patient was intubated, being initially manually ventilated, and started breathing spontaneously but remained unconscious for the next six hours. At admission in the $1 \mathrm{CU}$, her arterial blood pressure was $95 / 70 \mathrm{mmHg}$, and her oxygen saturation was 93\%. The patient received oxygen support, which was discontinued when oxygen saturation was above $96 \%$ and her arterial blood pressure was normal. Initially, the patient was treated with dextrose saline intravenous infusion, aspirin, systemic corticosteroids, and diazepam. Right bulbar deviation, tonic spasm of the right arm, and flaccid paralysis on the left side were found. There was a negative Babinski sign on the left.

Brain magnetic resonance imaging demonstrated ischemic brain lesions in the right frontal cortex without signs of hemorrhage or cerebral metastases. Subsequently, ECG showed deep negative T waves in anterolateral leads (Figure 1B) with mildly increased troponin levels (troponin T, $0.270 \mu \mathrm{g} / \mathrm{L}$ ). Transthoracic echocardiography revealed characteristic findings: ejection fraction of 45\%, hypokinesis of apical and mid segments, and hiperkinesis of basal segments of the left ventricle-apical ballooning syndrome (Figure 2). Follow-up laboratory tests showed no pathological findings indicating secondary hepatic or renal impairment. Supportive treatment with an angiotensin-converting enzyme inhibitor, a betablocker, aspirin, and a diuretic resulted in a decrease in troponin levels within $24 \mathrm{~h}(0.130 \mu \mathrm{g} / \mathrm{L})$ and clinical improvement. The patient stayed 4 days in the ICU followed by 27 days of hospital stay.

The patient suffered serious neurological damage with left-sided hemiplegia, but subsequent tests revealed normalization of cardiologic findings and normal ECG (Figure 1C). During hospitalization, no recurrence of hemoptysis was found. Neurological rehabilitation of the patient was conducted after discharge.

Flexible bronchoscopy is a diagnostic and interventional technique, widely used for various pulmonary pathologies. Introduced in the late 1960s, flexible bronchoscopy was recognized as one of the diagnostic and therapeutic cornerstones of pulmonary medicine. It is a safe procedure. In one recent retrospective study, the overall rate of serious complications was $0.5 \% .^{(1)}$ The most common complications were related to local anesthesia (0.3-0.5\%); hypoxemia (0.2-21.0\%); arrhythmias 
A)

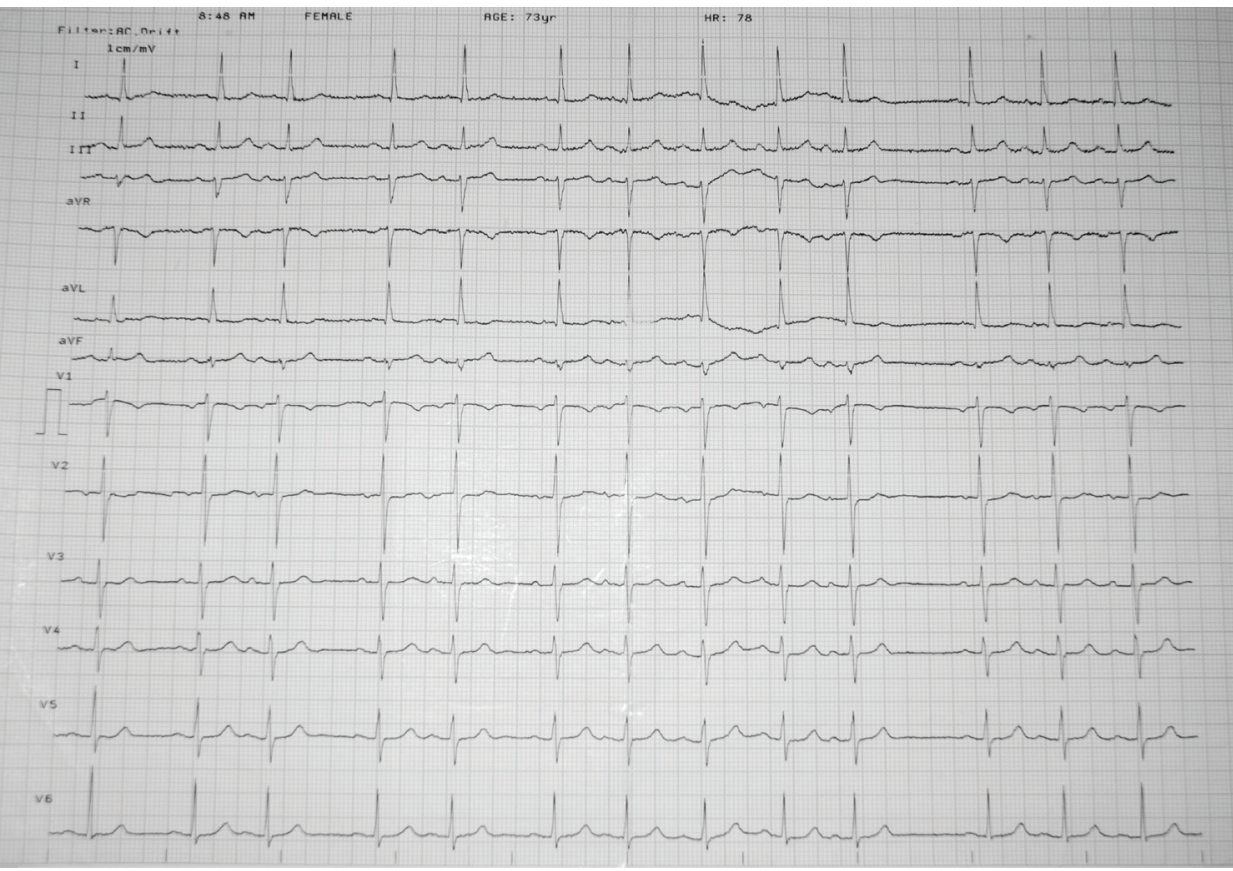

B)

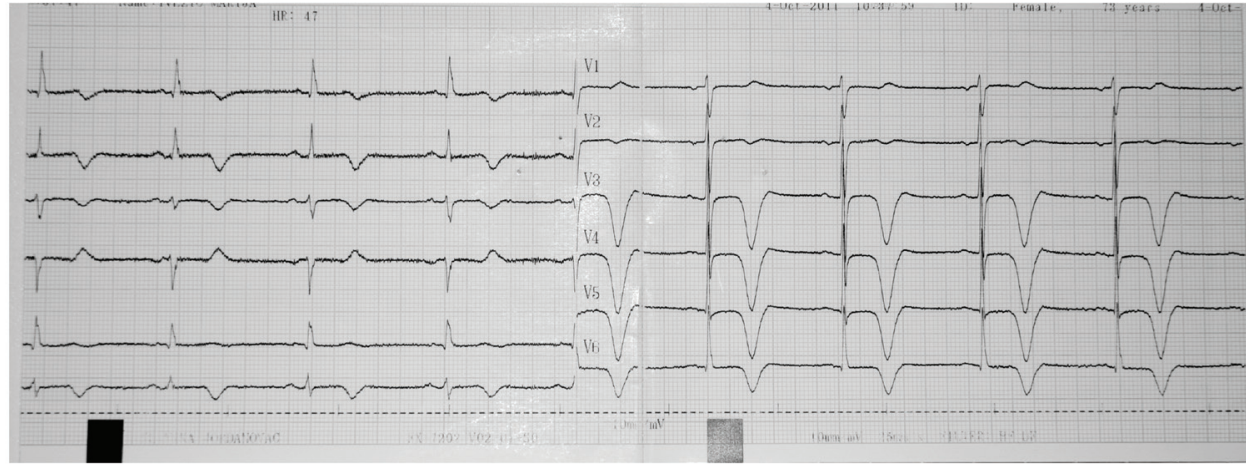

C)

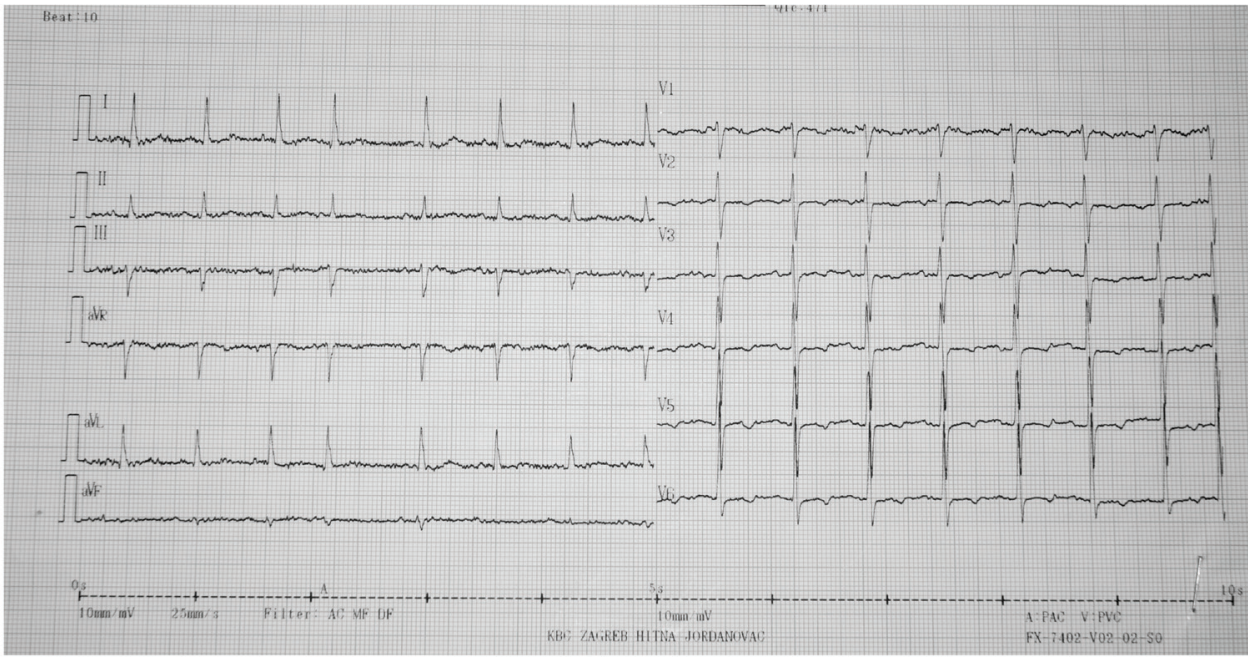

Figure 1 - Electrocardiograms. In A, normal sinus rhythm with one supraventricular ectopic beat and nonspecific ST-T segment abnormalities in precordial leads. In B, deep negative T waves in anterolateral leads. In C, slight sinus arrhythmia with no significant ST-T segment abnormalities. 


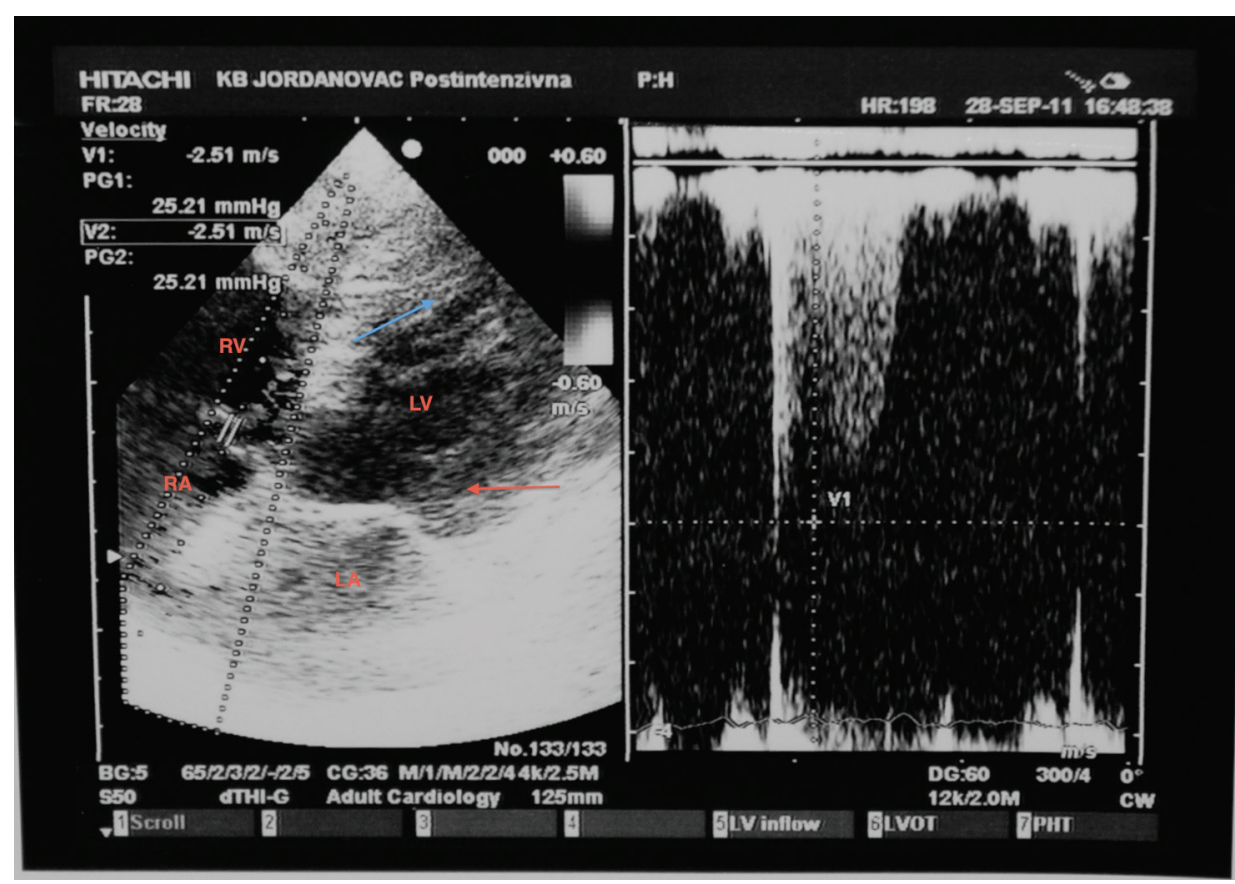

Figure 2 - Echocardiogram (four-chamber view) showing apical ballooning of the left ventricle (blue arrow) and hyperkinesis of basal segments in the left ventricle (red arrow). LA: left atrium; LV: left ventricle; RA: right atrium; and RV: right ventricle.

(1-10\%); bleeding following biopsy (0.12-7.50\%); pneumothorax/pneumomediastinum (1-6\%); and fever (0.9-2.5\%). Death occurs in $0.1-0.2 \%$ of the cases. ${ }^{(2)}$ One of the few serious complications that exceptionally might occur during the procedure is the development of ischemic cerebrovascular stroke secondary to disordered heart rhythm, hypoxemia, or air embolism. ${ }^{(1,2)}$

Stress cardiomyopathy, which is recognized as a unique form of transient cardiomyopathy and was first described in $1990,{ }^{(3,4)}$ is a reversible cardiac impairment that mimics an acute ischemic cardiac event without significant pathomorphological changes in the coronary arteries. ${ }^{(3)}$ Stress cardiomyopathy has the following characteristics: new ST-segment abnormalities on ECG (elevation and/or T-wave inversion), modest elevation in myocardial lesion biomarkers (troponin 1, troponin $\mathrm{T}$, and creatine kinase MB), transient left ventricular dysfunction, echocardiographic signs of hypokinesia/akinesia, and ballooning of the apical part of the left ventricle with reduced left ventricular ejection fraction. ${ }^{(4,5)}$

Stress cardiomyopathy can occur after acute mental or physical stress, subarachnoid hemorrhage, ischemic stroke, major head trauma, acute medical illness, pheochromocytoma exacerbation, and as a result of exogenous catecholamine administration. ${ }^{(6-9)}$
The pathophysiological mechanisms for the development of these disorders are not fully understood, but there is evidence of elevated levels of catecholamines, which indicates a connection with previously experienced extreme stress. ${ }^{(10)}$ All of the changes are reversible, supportive care is usually sufficient, and normalization of the left ventricle function can be expected within 1-3 months. ${ }^{(8)}$

Our patient experienced a rare sequence of complications during and after fiberoptic bronchoscopy. 1t is known that cerebrovascular and cardiovascular complications are more common in oncology patients, but this particular order of complications deserves attention. Since the patient presented with hemoptysis, it was extremely important that the correct diagnosis of transient cardiomyopathy was made because of the potential risk of recurrent bleeding in case the stress cardiomyopathy had been mistaken for acute coronary syndrome and anticoagulant therapy had been introduced. Therefore, familiarity with and awareness of potential complications, appropriate diagnostic tools, and management knowledge are paramount to successful treatment of such events. To our knowledge, this is the first reported case of such a sequence of bronchoscopy-related complications in one patient. 
Sonja Badovinac

Physician, Department of Respiratory

Diseases, University Hospital Centre

Zagreb, University of Zagreb School of

Medicine, Zagreb, Croatia

Marta Korsic

Physician, Department of Respiratory

Diseases, University Hospital Centre

Zagreb, University of Zagreb School of

Medicine, Zagreb, Croatia

Branka Cucevic

Head, Department of Pulmonary

Oncology, University Hospital Centre

Zagreb, University of Zagreb School of Medicine, Zagreb, Croatia

\section{Valentina Slivnjak}

Physician, Department of Cardiology, Hospital for Medical Rehabilitation Krapinske Toplice, Krapinske Toplice, Croatia

\section{Andrea Vukic Dugac}

Physician, Department of Respiratory

Diseases, University Hospital Centre

Zagreb, University of Zagreb School of Medicine, Zagreb, Croatia

Marko Jakopovic

Head, Department of Pulmonary

Circulation, University Hospital Centre

Zagreb, University of Zagreb School of Medicine, Zagreb, Croatia

\section{References}

1. Pue CA, Pacht ER. Complications of fiberoptic bronchoscopy at a university hospital. Chest. 1995;107(2):430-2. http:// dx.doi.org/10.1378/chest.107.2.430

2. Geraci G, Pisello F, Sciumè C, Li Volsi F, Romeo M, Modica G. Complication of flexible fiberoptic bronchoscopy. Literature review [Article in Italian]. Ann ltal Chir. 2007;78(3):18392. PMid:17722491

3. Akashi YJ, Nakazawa K, Sakakibara M, Miyake F, Koike H, Sasaka K. The clinical features of takotsubo cardiomyopathy. QJM. 2003;96(8):563-73. http://dx.doi.org/10.1093/ qjmed/hcg096 PMid:12897341

4. Prasad A, Lerman A, Rihal CS. Apical ballooning syndrome (Tako-Tsubo or stress cardiomyopathy): a mimic of acute myocardial infarction. Am Heart J. 2008;155(3):408-17. http://dx.doi.org/10.1016/j.ahj.2007.11.008 PMid:18294473

5. Gianni M, Dentali F, Grandi AM, Sumner G, Hiralal R, Lonn E. Apical ballooning syndrome or takotsubo cardiomyopathy: a systematic review. Eur Heart J. 2006;27(13):1523-9. http://dx.doi.org/10.1093/eurheartj/ehl032 PMid:16720686

6. Ako J, Sudhir K, Farouque HM, Honda Y, Fitzgerald PJ. Transient left ventricular dysfunction under severe stress: brain-heart relationship revisited. Am J Med. 2006;119(1):10-7. http:// dx.doi.org/10.1016/j.amjmed.2005.08.022 PMid:16431176

7. Lee VH, Oh JK, Mulvagh SL, Wijdicks EF. Mechanisms in neurogenic stress cardiomyopathy after aneurysmal subarachnoid hemorrhage. Neurocrit Care. 2006;5(3):243-9. http://dx.doi.org/10.1385/NCC:5:3:243

8. Bybee KA, Prasad A. Stress-related cardiomyopathy syndromes. Circulation. 2008;118(4):397-409. http:// dx.doi.org/10.1161/CIRCULATIONAHA.106.677625 PMid:18645066

9. Yoshimura S, Toyoda K, Ohara T, Nagasawa H, Ohtani N, Kuwashiro T, et al. Takotsubo cardiomyopathy in acute ischemic stroke. Ann Neurol. 2008;64(5):547-54. http:// dx.doi.org/10.1002/ana.21459 PMid:18688801

10. Wittstein 1S, Thiemann DR, Lima JA, Baughman KL, Schulman SP, Gerstenblith G, et al. Neurohumoral features of myocardial stunning due to sudden emotional stress. N Engl J Med. 2005;352(6):539-48. http://dx.doi.org/10.1056/ NEJMoa043046 PMid:15703419 